Margarita Gaviria Mejía ${ }^{1}$ Eduardo Périco ${ }^{2}$ Laura Barbieri Oliveira ${ }^{2}$

\section{O papel das identidades culturais e dos serviços públicos de saúde no processo de municipalização ocorrido nas últimas décadas em pequenas localidades do Rio Grande do Sul, Brasil}

\author{
The role of cultural identities and public health services \\ in the municipalization process taken place in recent decades
} on small towns of Rio Grande do Sul, Brazil
Ciências Sociais e Jurídicas, Centro Universitário Univates. R. Avelino Tallini 171, Universitário. 95900000 Lajeado RS Brasil. margaritarosagaviria@ gmail.com

${ }^{2}$ Centro de Ciências Biológicas e da Saúde, Centro Universitário Univates.
Abstract The paper presents a preliminary results of an ethnographic study in which we observe how is socially experienced the municipality process in six counties of the Forqueta Watershed in Rio Grande do Sul, where the municipal fragmentation has been used as an administrative strategy since the 1990s. Deal about cultural elements and social actions that support construction and/ or reconstruction identities to define territoriescounty's borders. Sociological and anthropological theories have been used to think the identities and the assumption that the integration of social spaces into a territory creates the social necessity to produce a territorial identity, closely linked to a socio-political context and cultural setting. We realize that the decentralization process in small municipalities helps stem the rural exodus, being health services determinant in curbing the migratory flow that characterized these locations reality in recent decades as a result of the agribusiness growth. Today, in these same places, health services represent the main support of collective identity with the territory-county and, instead of emigration, stimulate the immigration.

Key words Identity, Territory, County, Cultural symbols, Public Health Services
Resumo O artigo mostra os resultados preliminares de uma pesquisa etnográfica na qual observamos como é vivenciado socialmente o processo de municipalização em seis municípios da Bacia Hidrográfica do Forqueta, no Rio Grande do Sul, onde a fragmentação de municípios tem se disseminado como estratégia administrativa desde a década de 1990. Discorremos acerca de elementos culturais e de ações sociais que dão suporte às identidades construídas e/ou reconstruídas na definição das fronteiras dos territórios-município. Teorias sociológicas e antropológicas foram utilizadas para pensar as identidades e o pressuposto de que a integração de espaços sociais num território cria a necessidade social de produção de uma identidade territorial estreitamente vinculada a um contexto sociopolítico e a uma configuração cultural. Percebemos que o processo de municipalização em pequenos municípios ajuda a conter o êxodo rural, sendo os serviços de saúde determinantes na contenção do fluxo migratório que caracterizava a realidade destas localidades, nas últimas décadas, em consequência do crescimento da agroindústria. Na atualidade, nesses mesmos locais, os serviços de saúde representam o principal suporte da identidade coletiva com o território -município e, no lugar da emigração, estimulam a imigração.

Palavras-chave Identidade, Território, Município, Símbolos Culturais, Serviços Públicos de Saúde 


\section{Introdução}

Tal como tem sido destacado por diversos analistas da sociedade contemporânea em suas obras ${ }^{1}$, o processo de globalização tem repercussões no "mundo como um todo"2, carregando consigo conflitos e contradições que provocam o avanço de identidades coletivas como desafio à globalização e ao cosmopolitismo.

As identidades coletivas, reativas, nos termos de Castells ${ }^{3}$, surgem da vontade de certos setores da sociedade de criar focos de resistência contra a estrutura das instituições políticas e jurídicas do Estado que não os representa, pois, nela, a sociedade civil carece de espaços de poder decisório em relação a fenômenos que a afetam. Essas identidades coletivas resultam também de reações contra o modelo cultural hegemônico disseminado pelos meios de comunicação de massa, propulsor de uma sociedade de consumo, heteromana; bem como, de um confronto contra poderes institucionais de ordem global sobre os quais a maior parte das pessoas não tem nenhuma inferência, já que, como disse Castells ${ }^{3}$, há uma desarticulação entre a lógica do poder na rede mundial e a representação nas sociedades e culturas particulares.

Perante esse descompasso entre a representação do poder mundial e a representação do poder local constroem-se identidades reativas manifestas na reivindicação de autonomia de certos setores sociais em projetos que almejam uma melhora nas condições físicas e materiais das localidades a que pertencem e na vontade de ampliar o espaço de participação em decisões políticas que os atingem localmente no cotidiano.

Apesar de serem inúmeras as situações de contestação no marco das quais as identidades se constroem, uma visão geral das mesmas evidencia que o processo de construção ou reconstrução de identidades é um mecanismo de proteção e/ou de projeção futura de sujeitos na atualidade. Os quais, para projetar-se, inserem-se à economia global a partir das possibilidades locais, dos recursos materiais e humanos de que dispõem. Para isso, recorrem aos mesmos recursos tecnológicos e de infraestrutura que os líderes da globalização utilizam para desenvolver uma sociedade totalizadora.

Através de entrevistas gravadas e transcritas, com integrantes de famílias dos locais, analisamos aqui a construção de identidades como mecanismos de proteção e projeção dos sujeitos, com foco em populações entre 2.000 e 6.000 habitantes, que não têm "aparentemente" nenhum controle sobre as mudanças sociais, econômicas e culturais globais, em vista de que muitas das decisões que as atingem ocorrem em espaços que ultrapassam as fronteiras de seus territórios. A esta situação nos referimos neste artigo tomando como base de reflexão as mudanças territoriais em localidades que se projetam e se protegem através da emancipação dos municípios de origem, centrando nossas observações na Bacia Hidrográfica do Rio Forqueta, do Rio Grande do Sul.

A relevância de refletir sobre a territorialização implícita na municipalização surgiu na pesquisa "Modelagem da fragmentação florestal da bacia hidrográfica do rio Forqueta, RS, para estabelecimento de corredores ecológicos e avaliação dos aspectos sociais envolvidos", desenvolvida na Univates. O trabalho começou como análise ecológica das características da região, centrado na avaliação da fauna e flora enquanto indicadores de qualidade ambiental e, posteriormente, passou a abranger os aspectos sociais das populações envolvidas. Durante o trabalho percebeu-se a necessidade de compreender como são vivenciadas socialmente as emancipações dos municípios, tanto por parte de quem passa a incorporar novos elementos de identidade municipal, quanto por aqueles que habitam municípios que perderam em espaço físico e social, ao serem divididos. Segundo Ribeiro ${ }^{4}$, os múltiplos olhares sobre o território contribuem para identificação e resolução de problemas priorizados de forma coletiva.

\section{O processo de municipalização no Rio Grande do Sul}

O processo de municipalização no Rio Grande do Sul não é recente. Uma revisão histórica do assunto mostra que este tem sido impulsionado por conjunturas históricas distintas. Uma delas remete-se a 1809 , quando são criados os primeiros municípios para demarcar limites de áreas de terra da monarquia luso-brasileira. A partir de então se dá a progressiva fragmentação desses territórios em novos municípios, primeiramente, fundamentada em interesses econômicos, e, após a colonização europeia, o fator que determina a formação dos municípios é o crescimento da densidade populacional. Ao final do século $\mathrm{XX}$, no período de transição entre a ditadura e a democracia, a municipalização é impulsionada pela Constituição Federal de 1988, que estabelece como um dos princípios básicos a descentralização do Estado Nação. No âmbito dessa proposta, o município passa a ser a menor instância política no território brasileiro, com poder político, exe- 
cutivo e legislativo próprio. E uma terceira conjuntura histórica corresponde à criação de municípios na última década do século XX e primeira do XXI, decorrente da expansão das instituições políticas estatais no território brasileiro, motivado por fatores políticos e econômicos diferentes, entre eles a crise socioeconômica, a resistência ao neoliberalismo e o consequente retorno ao Estado. Nesse contexto histórico, as configurações locais da economia globalizada valorizam o município como menor fração do Estado brasileiro 5 .

No Rio Grande do Sul, o referido processo intensifica-se desde a década de 1990, quando a fragmentação dos municípios se dissemina como estratégia administrativa, passa de 232 municípios, em 1974, para 497, em $2013^{6}$. A referida expansão, favorecida pela legislação, é controlada em 2010 através da Lei Complementar $13.587^{7}$ que estabelece maior rigor no processo de emancipação.

Contudo, ao longo da história do Rio Grande do Sul, do século XIX até o XXI, a emancipação municipal interessa enquanto permite a construção de uma estrutura política administrativa com autonomia. Representa um instrumento de dominação sobre um espaço físico e social, consolidado na criação de órgãos locais de poder político e social, estabelecidos de maneira consciente com a finalidade de alcançar maior desenvolvimento. Quer dizer, a fundação de um município, além de um quadro político e administrativo próprio, compreende comunidades que procuram através da independência administrativa favorecer as condições de desenvolvimento econômico e melhorar a qualidade de vida facilitando o acesso a serviços básicos como saúde, educação, saneamento básico, infraestrutura viária, entre outros. Com foco na saúde, os gestores públicos municipais visam combater as marcantes e crescentes desigualdades sociais diagnosticadas pela Pesquisa Avaliativa de Desigualdades em Saúde no Rio Grande do Sul (PADS-RS) ${ }^{8}$.

\section{Territorialização e identidades}

$\mathrm{Na}$ análise de elementos políticos, sociais e culturais envolvidos na construção de territórios municipais, partimos do pressuposto teórico de que em sociedades sujeitas a um novo aparato político administrativo instaura-se uma nova relação das pessoas com o território, deflagrando transformações em múltiplos níveis de sua existência sociocultural. Quer dizer, a presença de um novo quadro administrativo, a raiz da segmentação municipal, estabelece uma nova relação dos su- jeitos com o território ${ }^{9}$. Pois, seguindo Oliveira ${ }^{10}$, "a atribuição a uma sociedade de uma base territorial fixa se constitui em um ponto chave para a apreensão de mudanças porque ela passa, isso afetando profundamente o funcionamento das suas instituições e a significação de suas manifestações culturais". Baseados nos postulados deste autor, indagamos pelo processo de territorialização, isto é, a reorganização do espaço físico e social decorrente da municipalização e a forma como isso se reflete nos serviços públicos de saúde.

Um dos conceitos centrais para pensar a territorialização é o de identidade social, vista não como elemento fixo, mas em permanente construção e desconstrução. Percebe-se que no processo de renovação administrativa dos municípios, as identidades sociais se constroem e desconstroem. Nesse sentido, partimos da concepção teórica de identidade reflexiva, característica da sociedade contemporânea, desenvolvida por Hall $^{11}$. Desta ótica, a identidade se constrói num meio dominado pela diversidade em termos de contatos, diferenças e disputas que colocam cada sujeito, diante dos outros, individualmente e sem "comunidade" de pertencimento fixo, exclusivo ou definitivo. Situação que conduz à criação de uma identidade (individual ou coletiva) múltipla, inacabada, instável, sempre experimentada mais como uma busca do que como um fato. $\mathrm{O}$ sujeito assume identidades diferentes em momentos diferentes, identidades que não são referenciadas ao redor de um "eu” coerente. São identidades contraditórias, que lançam o sujeito em várias direções.

Embasados no referencial teórico sobre identidades na pós-modernidade ${ }^{11}$, analisamos as identidades sociais, contraditórias ou não, construídas na delimitação das fronteiras do território-município, que corresponde a um território social demarcado por práticas culturais e representações sociais em torno da "terra", reconfigurado por sua legitimidade perante o poder público como instância administrativa autônoma.

Assim, no artigo, tratamos primeiramente sobre as práticas culturais e representações sociais definidoras da identidade cultural com a terra sobre a qual se erige o projeto municipal, em vista de que a força do projeto municipal fundamenta-se na identidade coletiva com a "terra". E posteriormente discorremos acerca da identidade municipal, construída a partir da mobilização dos representantes do poder da localidade para administrar com diligência e autonomamente recursos públicos que possibilitem uma boa distribuição de serviços, entre os quais se destaca a 
saúde, mas, de modo geral, visam melhorar as condições de vida das populações.

\section{Identidades com a terra}

O projeto de municipalização se constrói com base numa identidade coletiva marcada pela história de vida em comum, por crenças religiosas, em suma, pelos contornos da cultura à que pertencem, no marco da qual se destaca o conteúdo simbólico da "terra". São descendentes de alemães e italianos que recriam valores ligados a suas respectivas etnias. Quanto aos alemães, eles preservam a aprendizagem da língua alemã transmitida de geração em geração; têm grupos de dança folclórica alemã, fazem construções arquitetônicas em estilo xaimel como símbolo da cultura material alemã. E a maneira dos italianos reforçar a identidade étnica é divulgando as cantorias italianas, a cultura alimentícia e as festas religiosas. Ambas as etnias partem dos materiais culturais a que têm acesso para definir sua posição na sociedade.

Contudo, as identidades são múltiplas e amplamente diversificadas, cada sujeito ou indivíduo pode ter várias identidades. Uma delas é a identidade com a terra, que consideramos estrutural, pois a categoria social "terra", utilizada no âmbito do espaço rural, equivale àquilo que o discurso acadêmico chama de território. E, seguindo as ponderações de Brandão ${ }^{12}$, "a terra demarca uma relação e marca uma identidade estabelecida através da qualidade de reciprocidade entre um tipo de ator frente a ela e o feixe de outros relacionamentos que ela e seus frutos geram e determinam”. Perpassa uma espécie de relação emocional, imperceptível, que liga os homens a sua terra, que acreditamos ser fundamental desvendá-la.

$\mathrm{Na}$ análise das relações com a "terra natal", no âmbito dos novos municípios, notamos que as mudanças de identidade em relação à terra de origem relacionam-se em parte com as transformações do espaço produtivo que vivencia o Rio Grande do Sul a partir dos anos 1970, momento em que o Estado passa a ser influenciado pela engrenagem do capitalismo financeiro e a produção em escala mundial que demanda a modernização da agricultura. O Rio Grande do Sul é pressionado a acompanhar o ritmo das mudanças investindo na agroindústria, enquanto que a rentabilidade da agricultura familiar diminui. Fenômeno que contribui para que pequenas localidades que se dedicavam a esse setor da produção passem a diversificar as atividades produtivas, tornam- se pluriativas. A pluriatividade ocorre quando agricultores e demais membros da família não praticam apenas atividades ligadas à agricultura em suas terras, desenvolvem também atividades econômicas fora da propriedade, dentro ou fora do setor agrícola ${ }^{13}$.

As mudanças na vocação econômica dos municípios recém-criados se refletem na paisagem física e social. Nesses espaços estabelecem-se indústrias que levam à transformação das relações de trabalho e à inserção de outros atores sociais. Com isso, o assalariamento na renda das famílias de agricultores fica mais forte, já que, os filhos dos agricultores optam por arrumar emprego em empresas e fixar suas residências perto do local de trabalho, rompendo com o padrão residencial do modo de vida agrícola, no âmbito do qual os filhos continuam a morar na propriedade da família, incluso depois de casar.

De um modo geral, nestes novos municípios as práticas agrícolas têm maior valor simbólico do que econômico. Quer dizer, no "interior”, a agricultura representa um suporte de identidade das comunidades com seus territórios. Esta prática, amplamente estendida, representa a prática de lavrar a terra, valorizada pela atividade em si: plantar, colher e comer do que plantam. Geralmente, para estes atores sociais, parte da produção se destina ao consumo e a maioria recebe aposentadoria e/ou ajuda dos filhos. Esse fato ilustra uma peculiaridade no significado da agricultura na contemporaneidade: é uma categoria polissêmica, de conteúdo econômico, cultural e social $^{13}$. Valorizada, não apenas como setor da economia, mas por sua dimensão imaterial, representa um modo de vida, marcado pelo sacrifício para quem o vive. Sobre essa ideia é ilustrativa a fala de um agricultor quando comenta que todos os irmãos migraram para outras atividades produtivas na cidade e que "o único morto" é ele que ficou na colônia.

Por ser um elemento de identidade fundamental e estruturante na construção dos territórios do interior, a prática agrícola recebe forte incentivo das autoridades municipais, que ajudam com subsídios, oferecem "sementes, incentivos, horas máquinas para os planares”. Essas autoridades também asfaltam as principais vias de acesso para facilitar o escoamento da produção agrícola. Contudo, há um descontentamento do setor da população que ainda atua no campo da agricultura em relação à tendência atual das administrações municipais em investir financeiramente em símbolos culturais como arquitetura colonial e festividades que beneficiam o setor turístico. 

produz uma mudança das representações do rural. Estudos sobre o assunto ${ }^{14}$ revelam uma pluralidade de sentidos atribuídos a essa noção na atualidade. O rural se refere a um espaço físico, a um espaço social, a uma imagem, a uma mentalidade, a um estilo de vida, à agricultura e/ou a outras atividades econômicas, à natureza, a um espaço de turismo e lazer. Em suma, seu conteúdo pode estar centrado no cultural, no ocupacional ou no ecológico ${ }^{14,15}$.

$\mathrm{O}$ amor pela natureza e o prazer de morar no campo se estendem por diversos setores da sociedade. Os indivíduos se identificam com um estilo de vida agrícola, definido pelas práticas agrícolas e o meio ambiente social e natural onde se desenvolvem essas práticas. Quer dizer, o rural ou $o$ interior, categoria utilizada no universo empírico estudado, é valorizado pela natureza das relações sociais ali concebidas e por seu espaço físico. $\mathrm{O}$ valorizam como espaço de moradia. Consideram que é mais fácil viver no interior do que na cidade por seus atributos naturais e pela qualidade das relações sociais. Outros atrativos de morar no interior são o custo de vida, o preço das propriedades e a possibilidade de estarem distantes de problemas sociais que afligem as cidades, como insegurança e privação de liberdade. Em suma, a "terra" passa a ter um valor simbólico, como espaço de habitação e de lazer. Fenômeno que contribui para que as propriedades de agricultores familiares se transformem em chácaras, áreas de lazer e de turismo.

A ressignificação social do "interior" tem levado a pequenos municípios, recém-criados, a elaborar projetos turísticos e residenciais para atrair pessoas de "fora", moradores das cidades para suas localidades. Paradoxalmente, o crescimento da população de fora nos novos municípios é um fenômeno que preocupa aos nativos dos lugares, pois a migração de gente de fora os deixa vulneráveis a problemas característicos das cidades, como violência e drogas.

Apesar de fatos como a inserção de pessoas de fora no município serem percebidas pelos nativos uma ameaça à tranquilidade e ao equilíbrio da vida, a maioria da população destaca os benefícios que traz a mudança de status do distrito para "município".

\section{Identidade municipal}

Dados da pesquisa revelam o afã de líderes sociais, políticos e moradores de distritos de se emanciparem daquilo que empobrece as condições de vida e os coloca em posições de desigualdade social em relação a outros espaços sociais. Apesar das divisões políticas entre os atores envolvidos no processo de municipalização, eles se empenham na campanha pela emancipação do "município mãe" com vistas a mudanças da estrutura organizacional das comunidades da localidade.

Grande contingente da população do interior gaúcho se mobiliza em torno da criação de um novo município, que implica na segmentação de um território social e político para dar lugar a um novo território cujas fronteiras são definidas a partir da construção de uma identidade local específica. Entendendo aqui por identidade a construção de sentido a partir de um atributo cultural, ou de um conjunto coerente de atributos culturais que têm prioridade sobre todas as outras fontes, mediante a delimitação de fronteiras com "o outro"3.

Como disse Oliven ${ }^{16}$, referindo-se ao caso brasileiro, a construção da identidade aparece estreitamente vinculada ao contexto sociopolítico. Para incorporar as transformações sociais, no âmbito dos novos municípios, se constrói uma identidade de projeto, "produzida por atores sociais que partem dos materiais culturais a que têm acesso, para redefinir sua posição na sociedade"3. Como fazem os moradores de um distrito quando projetam a construção municipal.

Os novos municípios se constroem sobre as velhas estruturas e funções dos distritos. Assim, a integração de bairros e distritos num todo unificado cria a necessidade social de produção de uma identidade de projeto municipal. Esse fenômeno se expressa em símbolos oficiais municipais, pois os elementos semióticos se alteram com a emancipação dos distritos. Simbologias locais como bandeira, escudo, brasão, emblema, selo e hino são criados e admitidos constitucionalmente com sua devida reverência.

Inspirados em teorias sociológicas e antropológicas clássicas utilizadas para pensar a identidade territorial, observamos que elementos semióticos de um município têm a função de simbolizar uma sociedade ao mesmo tempo que procura diferenciá-la de outras. Trata-se de identidades legitimadoras e legitimadas pelas instituições existentes, pelos aparatos do poder, que se traduzem em projetos de futuro ${ }^{3}$. 
A identidade municipal é uma identidade legitimada, destacada pelas pessoas como forma de empoderamento perante as instâncias estaduais e federais de administradores e da população em matéria de direitos cidadãos. Considerando principalmente a ampliação de recursos, em vista de que não precisam dividir mais "o bolo" com outros distritos. A fundação municipal dá direito a receber uma verba repassada pelo Estado e a Nação, e utilizá-la em prol do desenvolvimento da localidade. Outra das mudanças estruturais inerentes à municipalização é a instauração de um serviço público de saúde próprio. Já que, conforme a Constituição Federal brasileira, a saúde é um bem público e, como tal, todo município precisa ter a estrutura necessária para garantir aos cidadãos o direito universal a esse bem. Estatuto fundamentado no princípio de equidade social e de integralidade, que esbarra na dificuldade do reconhecimento e valorização do direito à integridade e à dignidade humana em sua expressão individual ou coletiva como fundamentos para a organização e regulação das intervenções públicas nas sociedades contemporâneas ${ }^{4}$.

\section{Serviços públicos de saúde municipal}

São muitas as mudanças que as pessoas lembram como fatores de melhora na qualidade de vida com a emancipação, mas, sobressaem as referências à elevação na prestação de serviços de saúde. Destacam a saúde como a mais significativa e positiva entre as mudanças territoriais da municipalização, já que não precisam mais se deslocar para o "município mãe" em caso de requerer consulta médica, como acontecia quando a localidade era distrito e contava unicamente com uma enfermeira e doze consultas médicas por semana para atender a população, e para conseguir serviços especializados, como ambulância, as pessoas precisavam de influência política.

Atualmente, têm acesso a médicos gerais e especialistas na sede do município gratuitamente e com maior facilidade, conseguem consulta "de um dia para outro". Os novos municípios passam a ter unidades de atendimento médico próprias, lideradas pela administração municipal em benefício da população local. Fenômeno eloquente no significado social desse serviço.

A melhor infraestrutura na área de saúde fez com que antigos opositores do projeto de emancipação mudassem de posição e percebessem a vantagem da criação do município, passando a incorporar o setor da população que reivindica a identidade municipal. Observamos também na pesquisa que o aprimoramento nos serviços da saúde representa um motivo de mobilização social, uma ferramenta de controle do êxodo rural e um fator de mudança nas relações dos médicos com os pacientes.

Por um lado, as pessoas se mobilizam para marcar uma identidade de pertencimento ao município que lhes dá direito a ter acesso a serviços de saúde, é o caso das que nasceram na localidade e foram morar em outros municípios, próximos geograficamente. Elas procuram atendimento de saúde no local de nascimento, uma vez que a qualidade dos serviços de saúde nesse município é melhor do que onde moram.

O fato da identidade de pertencimento ao município dar à pessoa o direito à saúde, em alguns casos causa desgosto na população local e nas autoridades, já que as pessoas usufruem um serviço pelo qual não pagam. As autoridades dos municípios contemplados neste estudo reclamam da situação em que eleitores que moram fora do município têm acesso a serviços de saúde sem pagar impostos, "infelizmente só vêm para tirar”, disse um prefeito.

Para contornar o problema, os conselhos de saúde municipais compostos por representantes de diversos setores da sociedade que atuam nos municípios se debruçam sobre a situação de conflito apontada acima. Reúnem-se para examinar questões relacionadas à saúde, entre eles, a delimitação dos critérios que definem quem tem direito aos serviços de saúde e o destino da verba municipal para o setor.

Contudo, a saúde não é só um fator de mobilidade para os municípios pequenos de nativos que moram fora dele, mas também de pessoas oriundas de outros municípios. Neste caso, tratase de migrantes de cidades maiores que saem do município onde moram, às vezes, devido a que o amplo contingente populacional torna difícil o acesso à saúde, pela grande quantidade de usuários que demandam desses serviços. Já no novo município para serem atendidos não precisam esperar nem chegar de madrugada como ocorre em cidades de alta densidade demográfica. Perpassa a ideia de que enquanto menor o município, maior a possibilidade de a população receber atendimento médico rápido e de qualidade. No entanto, nem sempre os migrantes provêm de municípios grandes, alguns chegam de municípios pequenos que contam com escassos recursos para a saúde.

Ao mesmo tempo em que a boa qualidade de vida dos novos municípios, como resultado da ampliação dos recursos e serviços na saúde e da 
melhora em infraestrutura viária, educacional e habitacional, entre outras, estimula a migração de pessoas de fora para as pequenas localidades, ela controla o êxodo rural. Como apontam as análises dos discursos sobre o assunto, uma das consequências da mudança de status das localidades é o estancamento do êxodo rural. Embora o êxodo impulsione a ação governamental, mediante a elaboração de políticas públicas, os dados empíricos, em pequenos municípios, evidenciam que este problema se resolve oferecendo serviços públicos de qualidade para as populações.

A eficiência estrutural na área da saúde se observa nos recursos materiais e humanos de que dispõem os municípios e na qualidade do atendimento. Nos postos de saúde, além de médicos gerais e de especialistas, as administrações municipais oferecem serviços odontológicos, de fisioterapia, de psicologia e de nutricionista. Bem como a população tem direito a dois tipos de atendimento domiciliar. Um dos atendimentos é realizado por enfermeiras e técnicas de enfermagem que fazem curativos, verificam a pressão arterial, a taxa de glicemia e aplicam injeções, em suma, resolvem problemas considerados menos graves. E o outro tipo de atendimento é a visita médica domiciliar da enfermeira e do médico a pessoas doentes, acamados e idosos.

O referido atendimento domiciliar expressa que a relação profissional sobrepõe-se à relação pessoal. Para o paciente, o médico não é apenas um profissional, é alguém com quem estabelece uma relação social próxima. Essa proximidade social com os médicos se estende para os demais prestadores de serviços de saúde. No entanto, a proximidade social não significa ausência de hierarquia entre os sujeitos da relação. Os médicos têm poder social, que se reverte em poder político quando se candidatam a cargos públicos nos municípios onde atuam profissionalmente, mas de onde não são oriundos, geralmente. Fato que reforça a interferência da política local nas relações sociais que se constroem em municípios pequenos.

Nas relações médico paciente é eloquente uma das marcas das relações de proximidade social que caracteriza a sociabilidade em municípios pequenos, onde as relações profissionais se misturam às pessoais. Assim, o relacionamento das populações com as autoridades é de proximidade social. Prefeitos, secretários e vereadores nasceram e moram nos municípios que governam, portanto, perambulam pela localidade, comparecem a festas e a outros ambientes de sociabilidade como campo de futebol e a Igreja onde interagem com a população. As autoridades municipais e as populações estão unidas por um passado comum, vínculo que às vezes é reforçado por relações de parentesco e/ou de vizinhança. De maneira que, quando as pessoas precisam solicitar um serviço público ou fazer reivindicações, o fazem diretamente às autoridades, sem intermediários.

Contudo, a proximidade social faz com que a população sinta que a adesão política seja condição de acesso aos serviços de saúde. Na pesquisa percebemos que nas eleições municipais, as pessoas não declaram o voto entre familiares. Não assumem posição política contrária à das autoridades porque sentem medo de perder o acesso a serviços. Isto é, no imaginário social, quando se assume posição contrária ao governo municipal, os opositores não recebem fichas para o atendimento a serviços de saúde, nem têm acesso aos diversos serviços públicos municipais.

Essa personalização nas relações, a que nos referimos antes, se percebe na prestação de serviços de ambulância. A ambulância busca a pessoa na casa, tanto em casos de emergência, em situações de impossibilidade de locomoção, quanto em situações nas quais os servidores públicos da área da saúde conhecem a rotina e as necessidades da família. Sabem que os membros da família precisam trabalhar, seja na lavoura ou em outra área de atuação econômica, e, se suspendem a rotina para transportar um familiar para o local de atendimento (posto de saúde ou hospitais conveniados de cidades próximas ou de Porto Alegre, capital do Estado), vão ter prejuízo financeiro.

Paralelamente, a proximidade social entre servidores públicos e a sociedade civil permite que esta última exerça vigilância sobre as ações dos governantes no município, em consequência, um controle social. Situação que evoca o poder social da população em pequenas localidades, que, em alguns contextos, se impõe sobre o poder político-administrativo de prefeitos e demais autoridades municipais. Imposição subjacente no enquadramento do prefeito como funcionário. Contudo, esse confronto de forças de poder não é ausente de tensões e conflitos.

Quer dizer, a territorialização que acompanha a emancipação municipal não é benéfica em todos os aspectos, nem vivenciada sempre de maneira pacífica. Por um lado, áreas que antes da municipalização eram classificadas de rurais na condição de distrito, se tornam urbanas. Ocorre um rearranjo territorial que se reflete em novos e altos tributos para a população, em que o setor social mais afetado é o que pratica a agricultura 
familiar, pois, com as mudanças territoriais, as propriedades dos agricultores familiares, que estavam em espaços classificados de rurais quando era distrito, são classificados de urbanos após a emancipação, tendo que pagar tributos por isso. Por outro, a estrutura econômica do novo município não é independente do Fundo de Participação dos Municípios repassado pelo governo federal, dependendo de recursos externos para desenvolver programas e projetos.

Também, a criação de um município abre a brecha para divisões entre os membros das comunidades dos antigos distritos. Antes das primeiras eleições para prefeito, não havia divisões políticas visíveis. Mas, à raiz dos processos eleitorais elas tornam-se evidentes. Os moradores começam a se articular em torno de um candidato e se afiliar a um partido, ocasionando muitas vezes rupturas com vizinhos e familiares. Tal como alguns intelectuais demonstram em pesquisas sobre o assunto ${ }^{17}$, em pequenas localidades rurais ou urbanas, no "Tempo da Política", as pessoas se separam porque se envolvem nas campanhas. O período eleitoral representa o momento liberado para "conflito aberto" entre os partidos ou facções, mas, uma vez terminado esse período, fora do "Tempo da Política", tudo volta ao normal, restabelece-se a unidade social que a identidade municipal representa.

\section{Considerações finais}

Uma das questões que deve ser salientada entre as observações feitas durante a pesquisa é que o processo de municipalização ocorrido em pequenas localidades, entre 2.000 e 6.000 habitantes, leva a frear um dos fenômenos que mais preocupa aos Estados, não só no Brasil, mas em diversas partes do mundo: o êxodo rural. Sendo um dos principais responsáveis por esse freio os serviços públicos da saúde oferecidos nestes territórios. Ao ponto que a saúde passa a ser o eixo a partir do qual se erigem e se mantêm os políticos no poder executivo e legislativo dos municípios. Pois é o único segmento da vida social em que há um consenso acerca de ser prioridade de investimento municipal. Nos demais setores há posições divergentes acerca das preferências em investimento, oscilam entre o setor turístico, a agricultura familiar, a urbanização e a cultura. Enfim, perpassa a ideia de que os serviços de saúde representam o principal elemento de suporte de identidade coletiva em que se sustenta um "Projeto Municipal".

\section{Colaboradores}

MG Mejía, E Périco e LB Oliveira participaram igualmente de todas as etapas de elaboração do artigo. 


\section{Referências}

1. Giddens A. As consequências da modernidade. São Paulo: Editora da Universidade Estadual Paulista; 1991.

2. Robertson R. Mapeamento da condição global: globalização como conceito central. In: Featherstone M, organizador. Cultura global - nacionalismo, globalização e modernidade. Rio de Janeiro: Vozes; 1994. p. 23-39.

3. Castells M. O Poder da Identidade. São Paulo: Ed Paz e Terra; 1999. Vol II.

4. Ribeiro PT. Direito à saúde: integridade, diversidade e territorialidade. Cien Saude Colet 2007; 12(6):15251532.

5. Aragão WM. Implantação de assentamentos e criação de municípios: ocorrência e as causas de um efeito territorial imprevisto no Rio Grande do Sul das décadas de 80 e 90 do século XX [tese]. Porto Alegre: Universidade Federal do Rio Grande do Sul; 2013.

6. Instituto Brasileiro de Geografia e Estatística (IBGE). Pesquisa de Informações básicas municipais: perfil dos municípios brasileiros, 2013. [acessado 2014 maio 25]. Disponível em: ftp://ftp.ibge.gov.br/Perfil_Municipios 2013/munic2013.pdf

7. Brasil. Lei $n^{\circ} 13.587$ de 22 de dezembro de 2010. Dispõe sobre a criação, a incorporação, a fusão e o desmembramento de municípios, nos termos do art. $18, \$ 4^{\circ}$, da Constituição Federal e do art. 9. ${ }^{\circ}$ da Constituição do Estado, e dá outras providências. Diário Oficial da União 2010; 22 dez.

8. Drachler ML, Côrtes SMV, Castro JD, Leite JCC. Proposta de metodologia para selecionar indicadores de desigualdade em saúde visando definir prioridades de políticas públicas no Brasil. Cien Saude Colet 2003; 8(2):461-470.

9. Najar AL, Marques EC. A sociologia urbana, os modelos de análise da metrópole e a saúde coletiva: uma contribuição para o caso brasileiro. Cien Saude Colet 2003; 8(3):703-712.
10. Oliveira JP. A etnologia dos "índios misturados", situação colonial territorialização e fluxos culturais. Mana 1998; 4(1):47-77.

11. Hall S. A Identidade Cultural na Pós-modernidade. Rio de Janeiro: DP \&A; 2001.

12. Brandão CR. O afeto da terra. Campinas: Unicamp; 1999.

13. Schneider S. A abordagem territorial do desenvolvimento rural. Sociologias 2004; 1(1):88-125.

14. Carneiro MJ. O ideal urbano: campo e cidade no imaginário de jovens rurais. In: Silva T, Carlos F, organizadores. Mundo rural e política. Rio de Janeiro: Campus; 1998. p. 95-117.

15. Duran FE. Viejas e Nuevas imágenes sociales de ruralidad. Estud Soc Agric 1998; 11(2):76-98.

16. Oliven RG. A parte e o todo: a diversidade cultural no Brasil-Nação. Petropólis: Vozes; 1992.

17. Palmeira M. Voto: Racionalidade ou Significado. Rev Bras Ciênc Soc 1992; 20(7):26-30.

Artigo apresentado em 06/06/2014

Aprovado em 15/10/2014

Versão final apresentada em 17/10/2014 
